\title{
Organization of physics content knowledge for teaching purposes: From knowledge justification schemes to didactical schemes
}

\author{
Maija Nousiainen \\ Department of Physics, University of Helsinki, Finland \\ For correspondence: maija.nousiainen@helsinki.fi
}

\begin{abstract}
Argumentation in teaching and its centrality in higher education has been noted to be important. The logical order of presented content knowledge and soundness of reasoning are both essential parts of well-planned teaching. Even though coherent and sound argumentation is essential, even more important is the ability to reorganize the content structure for teaching purposes. This study investigates pre-service physics teachers' knowledge justification schemes (identification of content knowledge) and didactical schemes about four different topics on quantum physics. The data is collected from a physics teacher preparation course which attended of $\mathrm{N}=16$ pre-service physics teachers'. The knowledge justification schemes (KJS) and didactical schemes (DS) were evaluated and scored. Each pre-service teachers' scores of KJS's and DS's were summed up and normalized from 0 to 1 . The results suggest that successful identification of content knowledge (quality of KJS) is a pre-requisite qualified didactical scheme but the opposite never happens. The results offer new kind of understanding how scientific argumentation can be implemented in higher education and especially in teacher education. The possibilities to use argumentation as a teaching method as well as method to learn scientific knowledge in teacher education is discussed.
\end{abstract}

Keywords: knowledge justification, argumentation, didactical reconstruction of knowledge

\section{Introduction}

Scientific argumentation plays a central role in learning the form, structure and nature of scientific knowledge (Rapanta et al., 2013; Fischer et al., 2014). However, it has been noted that students find it difficult recognize the situations to use argumentative justification even though the basic argumentative moves might be familiar from daily life, e.g. politics (Cavagnetto \& Kurtz, 2016; Garcia-Mila \& Andersen, 2008). This motives to think that science teacher education paying more attention to teaching of argumentation as an instructional method but also as a learning method would be successful. However, argumentation is rarely used as a part of practical teaching. (Fischer et al., 2014; Knigh-Bardsley \& McNeill, 2016) There can be many explanations for the present state but one quite obvious reason might be teachers' uncertainty to use argumentation in their teaching which will explain their unwillingness to teach students how to construct arguments or how to use argumentation (Zohar, 2008; Knigh-Bardsley \& McNeill, 2016). This could be a good possibility for teacher education to step forward and offer qualifications for argumentation so that pre-service teachers would have substantial skills regarding both technical and pedagogical use of argumentation.

Argumentation studies usually aim to either learning-to-argue or arguing-to-learn (Rapanta et al., 2013). In this study these both goals and directions are taken as equally important in promoting pre-service physics teachers' better skills to identify basic argumentative moves and structures, to construct coherent arguments and employ argumentation in their future teaching. To this end, this study 
introduces knowledge justification schemes and employ them as a tool to teach argumentation and argumentative structure by paying special attention to justification of knowledge claims. Knowledge justification scheme is a graphical representation of the argumentative structure of justification of knowledge claim.

Coherent and sound argumentation is essential in teaching, but however, even more important is the ability to reorganize the content structure for teaching purposes (Duit et al., 2014; Nousiainen, 2013). Physics knowledge is complex; it is organised and has a structure, whereby meaning of physics concepts builds up essentially through the structure. Learning such complex content knowledge forms also a basis to learn coherent argumentation on subject matter knowledge. Clear exposition of new concepts, clear direction of progress, where new concepts are learned based on previously explained concepts, and clarity in how concepts become related are key features of well-organised physics content which a physics teacher should have in command. These aspects are trained by implementing didactical schemes which help pre-service physics teachers' to organise their understanding of physics conceptual structure and reflect how such structure is built in teaching. Didactical schemes can be regarded as argumentative structure of a teaching plan which combines both content knowledge and justification of that content knowledge. Again, didactical scheme is also a graphical representation of the teaching plan. The emphasis on graphical representation of knowledge is justified by the shared notion of their usefulness in forming "the big picture" of the relational knowledge structure in physics (Nousiainen, 2013; Mäntylä \& Nousiainen, 2014). The novelty of this research is paying attention to the justification of knowledge claims as a teaching method but also a method to focus on physics content knowledge.

These argumentation skills being justifying of knowledge claims and constructing a didactical presentation of justified knowledge are connected but not identical skills. A previous research has identified criteria to assess the quality of didactical schemes (Nousiainen, 2013) but how such ability to produce a qualified didactical scheme is connected to the ability to produce a qualified knowledge justification scheme is an unanswered question. Research questions of this study then are

RQ1: How the quality of knowledge justification schemes and didactical schemes can be measured?

RQ2: Is the quality of knowledge justification scheme an adequate precondition for building up a good didactical scheme?

This is answered by evaluating pre-service physics teachers' knowledge justification schemes and didactical schemes which they constructed during a teacher preparation course spring 2016. The instructor implemented the flipped classroom approach as her teaching method (Velegol et al., 2015; Toivola \& Silfverberg, 2015). In flipped classroom students have to investigate the topic at hand by reading given material or watching suitable videos before classroom activities. In such an approach the role of the instructor is to facilitate fruitful discussions by conceptual questions, by participating actively into students' group working and by providing extra material when needed. This approach gives students more responsibility of their own learning and emphasises learning of higher cognitive skills instead of listening and remembering which can be deemed as the setup of "traditional" lectures. In what follows it is important to remember that none of the topics were taught by the instructor (in the sense we traditionally understand teaching) since these topics were covered already in the introductory physics courses which these students have passed.

The teaching method supports the production of knowledge justification schemes and didactical schemes but also ensures that the students really represent their own views in their schemes. The quality of knowledge justification schemes are evaluated according to their basic argumentative parts being e.g. objective, evidence and conclusion (van Lacum et al., 2014) whereas the epistemic quality of didactical schemes is investigated by employing an epistemic framework (Nousiainen, 2013). The 
results offer new kind of understanding how scientific argumentation can be implemented in higher education and especially in teacher education.

\section{From scientific argumentation to argumentation in teaching}

Argument is a chain of reasoning to defend some theory or a point of view. Through argumentation the interlocutors try to convince each other by precise definitions of concepts and logical reasoning. An ideal argument is both logically faultless and rhetorically successful, and thus good argumentation is conceptually clear and has exact lines of reasoning between concepts. Argumentation can also be seen as a process (independent student or a collaborative learning situation) which involves general knowledge acquisition aiming at rational solving of questions, main issues and disagreements (Garcia-Mila \& Andersen, 2008).

Argumentation helps students to learn the form, structure and nature of scientific knowledge because it leads attention to justification of knowledge claims. (Rapanta et al., 2013; Fischer et al., 2014) Then the aim is to teach students to construct arguments that has a structure and form of scientific arguments. In other words, effort needs to be paid on learning to use of evidence to back up claims. Everyday argumentation is not a suitable model because its weakness is the inability to give any real arguments or counter arguments. Everyday argumentation typically just repeats the claim or appeal to the emotional state. (Sandoval \& Millwood, 2008)

One of the first frameworks modelling the scientific argumentation that was adopted for purposes of education has been suggested by Toulmin's (1958/2003) Argumentation Pattern, TAP. In TAP the argument has been divided in parts which are identified to be data, claim, warrant, backing, rebuttal and qualifier. TAP has provided basis for further extensions and there have been several attempts to revise Toulmin's framework for educational purposes. One of the most recent proposal suggests that argumentation can be taught by identifying argumentative moves from scientific texts (van Lacum et al., 2014). This heuristic, called Scientific Argumentation Model (SAM), consists of seven argumentative moves: motive, objective, support, main conclusion, counter argument, refutation and implication. The use of heuristic i.e. analysis on scientific texts is two-fold: identification of content knowledge and identification of how argumentation is presented in the text under inspection. Such an approach gives a promising and suitable tool to teach also pre-service teachers scientific argumentation paying special attention to justification of knowledge claims. In this study, this line of developing the argumentation further to match the needs of educational application is continued. These notions can be summarised as a set of guidelines.

\section{Guideline to construct the knowledge justification schemes}

The practical solution to teach argumentation is to let students get to know the form of scientific knowledge through scientific texts, i.e. original and authentic research articles. According to SAM (van Lacum et al., 2014) the argumentative moves which can be found in scientific texts are:

1 Motive: Statement indicating why the research was done (e.g., a gap in knowledge, contradictory results). The motive leads to the objective.

2 Objective: Statement about what the authors want to know. The objective may be formulated as a research question, a research aim, or a hypothesis that needs to be tested.

3 Main conclusion: Statement about the main outcome of the research. The main conclusion is closely connected to the objective. It answers the research question, it says whether the research aim was achieved, or it states whether the hypothesis was supported by evidence. The main conclusion will lead to an implication.

4 Implication: Statements indicating the consequences of the research. This can be a recommendation, a statement about the applicability of the results (in the scientific community or society), or a suggestion for future research. 
5 Support: The statements the authors use to justify their main conclusion. These statements can be based on their own data (or their interpretation) or can be statements from the literature (references). Supports may be presented in so-called support chains.

6 Counterargument: Statements that weaken or discredit the main conclusion. For example, possible methodological flaws, anomalous data, results that contradict previous studies, or alternative explanations. Counterarguments are sometimes presented as limitations.

7 Refutation: Statements that weaken or refute the counterargument.

These guidelines can be applied in practical teaching solutions since students' active and scaffolded working on the topic at hand fits very well in flipped classroom approach. The construction process is two-fold. First, students are given a research article and after reading it students are asked to identify the aforementioned argumentative moves. Second, students are asked to connect the moves to each other and present them as a graphical scheme. As a result students should produce, based on the given research article, a knowledge justification scheme which presents the main argument and its argumentative structure. When this is done, we have a clear summary of the main claims presented in the article and how they are motivated, supported and rebutted.

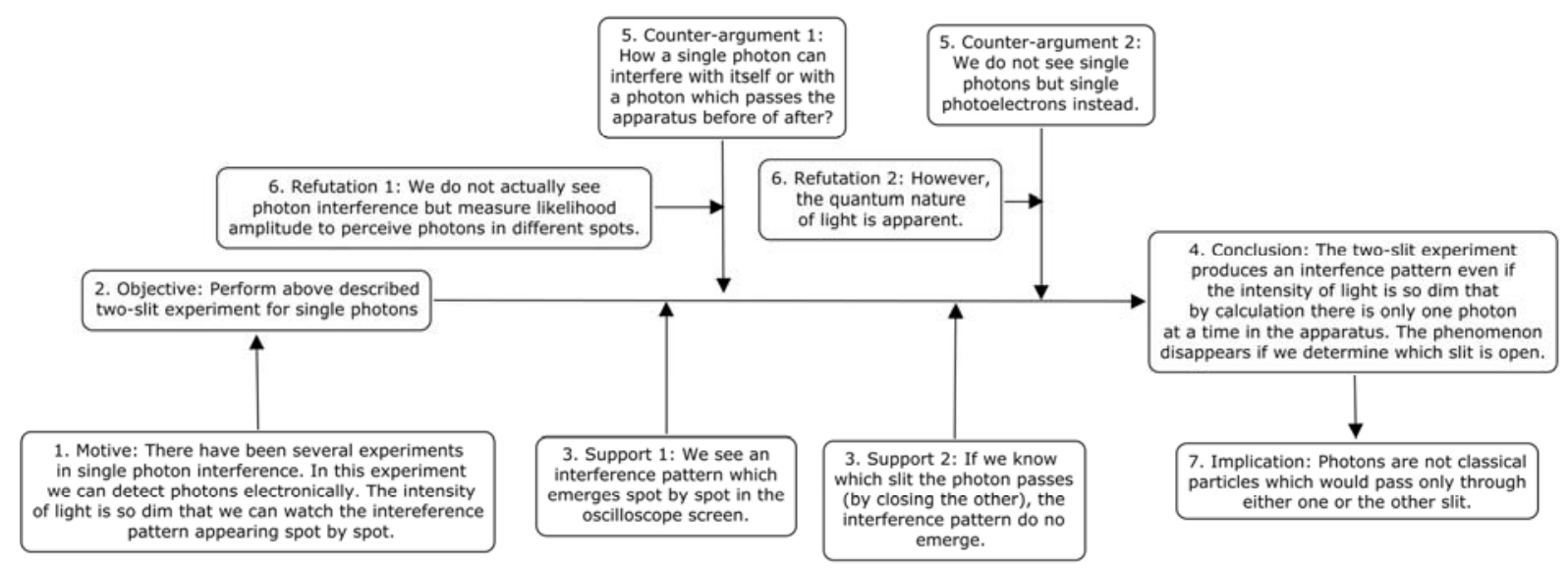

Figure 1. An example of a knowledge justification schema made by a student. Each box includes short description of the argumentative move identified from the given article which was about single photon interference.

In physics research articles the presentation of support (in form of different measurement results and their modelling) can be a complex chain of reasoning. The selected research articles deal with complex physics phenomena (detailed in Method chapter) and thus careful analysis on their argumentative structure is fruitful and useful practice in finding out the typical way physics knowledge is justified. Due to complexity of argumentation in the articles, the graphical outline of the argumentative structure as such scheme presumably helps students better to identify the argumentative moves since research has shown that graphical representation tools support one's metacognitive skills (Nousiainen, 2013).

\section{Didactical reconstruction of physics content knowledge}

In teaching physics the ability to reconstruct the epistemic point of physics knowledge (how do we know what we know) is of importance. In physics there are to main processes that build physics knowledge, namely experimental and modelling procedures. (Nousiainen, 2013; Nousiainen \& Koponen, 2010; Mäntylä \& Nousiainen, 2014) In the quantitative experiment, the concept is operationalised (made measurable through pre-existing concepts). The role of experiments and models can be exemplified by following description. For example, the operationalisation of 
Coulombs' law requires the concept of force and charge, whereas the concept of the electrical field rests on force, charge and Coulomb's law. ). In such experiments, a new concept or law is always constructed sequentially, starting from those that already exist and which also provide the basis for an experiment's design and interpretation. The results of the experiments and how they modify knowledge structures are usually expressed and represented in terms of models. Therefore, in addition to experiments, models are also core components of knowledge structures. For example, the definition of the electrical field is a model which breaks the force between two interacting charges into one part which causes the field (the charge as a source) and another part which experiences the field (the other charge). Typically, a model is an idealized and symbolic representation or a description of dependencies found in an experiment or that should provide explanations and predictions of regularities found in experimental data. (Koponen, 2007; Nousiainen \& Koponen, 2010)

In both knowledge construction processes the evidence that support the conclusions play an essential role. Therefore it is natural to assume that above described knowledge justification schemes can be useful starting point in planning the teaching of the topic. In addition to knowing content knowledge a core competence for a physics teacher is the ability to reconstruct the content knowledge, i.e. scientific knowledge needs to be outlined for teaching purposes (see e.g. Duit et al., 2014; Nousiainen, 2013). Such didactical outlines or reconstructions are needed for teachers to reflect on their own knowledge and plan their teaching in logical manner. Moreover, didactical reconstruction should be pay special attention to the epistemic aspects of argumentation. In other word, knowledge claims presented in such reconstruction need to be justified carefully and with thought. The epistemic aspects of argumentation are taken note by e.g. Fischer et al. (2014) being an important and fundamental viewpoint of the credibility of a claim. For example a fairy tale might be formally correct and coherent but it is not true. The following framework to reconstruct physics knowledge offers preservice physics teachers a suitable scaffold to reflect on their knowledge and present its structure as a scheme and give justifications for all the connections.

\section{Guideline to construct the didactical schemes}

A didactical scheme is a tool for pre-service physics teachers to reorganise their content knowledge for teaching purposes. It serves as a framework to plan teaching which core has central ideas from knowledge justification scheme but didactical scheme pays attention to organization and justification of knowledge in teaching. Didactical scheme presents how central quantities and laws form a tangled web of physics concepts. Special attention needs to be paid on the order in which concepts are presented and the relations between concepts. The concepts (nodes) are physics quantities, laws (either particular or general), models (e.g. definitions or analogies) or general principles (such as energy conservation) which are connected to each other with directed, numbered links. The direction and numbering of links shows the conceptual sequence according to which the conceptual structure is built. The scheme presents the relations between physics concepts, how these relations are established and how they are justified. The amount of nodes and links is not limited but the nodes have to belong in the given categories.

In practice the form of didactical scheme is a map (see Figure 2 for one example) representing the relations between concepts supplemented with a written report explaining the nodes and their connections in detail. For example, the description of experiments should include at least the motive or objective of the experiment, experimental setup, measurements and dependence or relation between concepts. In description of model one needs to explain the motive or aim of the model and how the model builds or ties up concepts. The written report supplements the illustrated relational structure of didactical scheme. 


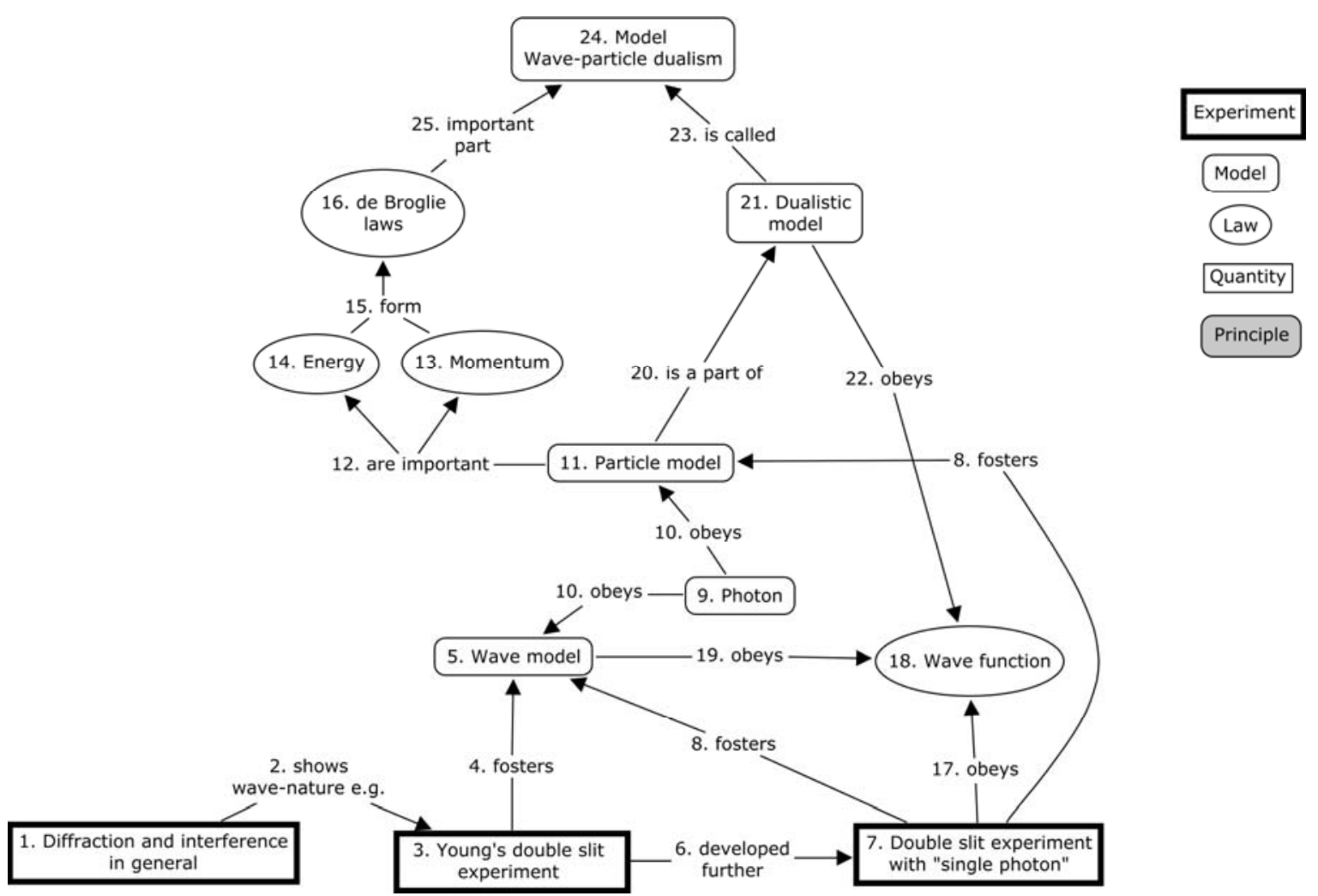

Figure 2. An example of a didactical scheme of single photon interference established by a pre-service physics teacher. Numbering refers to the order on how the graph should be read.

\section{Method}

Participants

The research was carried out spring 2016 during a teacher preparation course in the Department of Physics in the University of Helsinki. The course focused on organization of physics content knowledge in the context of quantum physics. The students $(\mathrm{N}=16)$ were pre-service physics teachers who were on their $3^{\text {rd }} 4^{\text {th }}$ year in their studies. The participants had already passed the basic level physics courses and the teacher preparation course at issue was a part of their obligatory intermediate physics teacher studies.

\section{Procedure}

The collected data were students' knowledge justification schemes and didactical schemes of introductory quantum physics. The four different topics were energy quantization, quantization of momentum and the augmentation of electron and photon concepts. The topics were chosen to be four most important experiments regarding quantization and particle-wave duality. The exact topics and research articles given as base material were

1. The photoelectric effect (Millikan, 1916): energy quantization and first impression of photon.

2. The scattering of $X$ rays (Compton, 1961): quantization of momentum, photon is needed to explain the phenomenon, concept of photon is specified with the understanding gained from photoelectric experiment.

3. The single photon interference (Rueckner \& Titcomb, 1996): the particle-nature of photon (experiment carried out by using very low intensity light) is needed to explain the phenomenon. The photoelectric and Compton's experiments are needed in interpretation of results. 
4. The single electron interference (Rosa, 2012): the wave-nature of electron shows up. The photoelectric and Compton's experiment and experiment on single photon interference are needed in interpretation of results.

The teaching proceeded in three phases. First students read a research article (listed above) and produced a knowledge justification scheme (KJS) according to the seven argumentative moves as indicated in van Lacum et al. (2014). The KJS's were assessed by instructor (method described in next section). Second, students evaluated and compared their schemes in small groups during the next lectures. When small groups had reached consensus of the main issues, students turned their thoughts towards teaching this topic in high school and discussed how the content should be reorganized for teaching purposes, e.g. what should be added or emphasized and what should be removed. Third, each student built their own didactical scheme about the topic. These three phases were employed to all four topics.

\section{Data analysis}

Data analysis of knowledge justification schemes

Knowledge justification schemes were analysed according to seven argumentative moves defined by van Lacum et al. (2014). Students schemes were compared to an expert KJS made by physics experts (three university teachers from Physics Department) how had read the research articles and constructed the KJS's of all four topics. The expert KJS's were very thorough and detailed, especially in how evidence were presented. Such thoroughness was not expected from students' schemes but in order to get full scores, the most important findings (that demonstrate how the argumentation proceeded in the article) were required. All moves were scored 0-1/2-1 and maximum score was 7 for each KJS. The example KJS shown in Figure 1 has scored full points in all argumentative moves. Partial scores were given if the move contained correct issue but it was somewhat superficially presented or if there were correct and incorrect information mixed with each other.

\section{Data analysis of didactical schemes}

Didactical schemes were analysed from two perspectives since the connectedness of the scheme (structure) and degree of epistemic justification of the concepts have both found to be important and inseparable features of well-organised knowledge structure. Degree of justified connections can be associated with the richness of organised knowledge and degree of epistemic explanations describes the quality of the knowledge. (Nousiainen, 2013) Moreover, unambiguousness of the scheme is an essential feature of good presentation. Therefore, the criteria to grade the $D S$ (max. 10 points) were as follows. In most cases the application of the criteria were straightforward but in some cases they could be applied only partially.

1. Framing (4 points). The didactical scheme is appropriately framed so that the relevant nodes are presented and they are justifiably linked.

2. Description of nodes (4 points). Justification of nodes is analysed by following epistemic justification criteria (explained shortly below and in detail in Nousiainen, 2013).

3. The clarity of the scheme (2 points). Nodes are categorised correctly into quantities, laws, experiments, models and principles. The scheme has a clear and well-defined starting point, has logical progression of concepts and justified ending.

Epistemic justification of explanations in students' reports (in form of description of nodes) is analysed using a specific taxonomy developed for this purpose and attention is paid only to following four epistemic aspects of knowledge: 1) ontology, 2) facts, 3) methodology and 4) valid justification (Nousiainen, 2013). The criteria are such that they are nearly self-evident prerequisites of acceptable knowledge in physics. Therefore, these four criteria form a suitable basis for the analysis of epistemic acceptability of knowledge represented in description of nodes: 
1. Ontology. Concepts are applied properly and they describe ontologically correct entities. Ontology also requires that the properties a quantity has are described adequately and that concepts are correctly related.

2. Facts. Appropriate and correct concepts are connected by presenting appropriate and correct quantities and laws that establish the connection. For a law or principle, the proper relation is given in a clear manner.

3. Methodology. In this approach methodological knowledge is limited to knowledge including the description of such experiments and models, which are feasible to make connections between physics quantities and laws.

4. Valid justification. Justified knowledge means that students gives ontologically correct, factually acceptable, and methodologically plausible arguments. For an experiment, this means that the prerequisites for the experiment are clearly and correctly described, that the experiment itself is adequately described (what is measured and how), and that results are expressed and conclusions discussed at some length. A similar sequence can also be followed in evaluating a model.

These criteria form cumulative, hierarchical ladders and thus the numbering (1-4) is indicative of the order in which the above epistemic "norms" should be fulfilled. All nodes were evaluated according to these criteria and average of the scores from all four DS's describes the overall epistemic quality of the justified knowledge student has in command.

\section{Results}

The knowledge justification schemes and didactical schemes were evaluated according to the above presented criteria. The maximum scores were 7 points for KJS and 10 points for DS. To ease the comparison, all scores were normalized between 0 and 1 .

Table 1. The average normalized scores of argumentative moves in students' knowledge justification schemes. Row numbers refer to argumentative moves: 1 . motivation, 2 . objective, 3. support, 4 . main conclusion, 5 . counterargument, 6 . refutation and 7. implication.

\begin{tabular}{ccccc}
\hline & KJS 1 & KJS 2 & KJS 3 & KJS 4 \\
\hline 1 & 0.72 & 0.72 & 0.91 & 0.91 \\
2 & 0.94 & 0.78 & 0.94 & 0.94 \\
3 & 0.50 & 0.78 & 0.88 & 0.84 \\
4 & 1.00 & 0.94 & 0.84 & 0.97 \\
5 & 0.81 & 0.97 & 0.72 & 0.75 \\
6 & 0.84 & 0.97 & 0.81 & 0.81 \\
7 & 0.94 & 0.97 & 0.91 & 0.84 \\
\hline
\end{tabular}

Results show that the average scores from knowledge justification schemes improve from 0.82 to 0.88 . In the first KJS the identification of the empirical support has been difficult. Closer inspection reveals that 6 out of 16 students have identified it correctly, 4 partially and 6 were not able to express empirical support at all or too superficially. One possible reason to this might be the demanding research article or students' limited understanding of the new type of task (first KJS). Otherwise there are no significant differences between KJS' scores. Typically main conclusion (average 0.94), objective and implication ( 0.90 and 0.91 , respectively) are best identified in students' KJS.

Students have succeeded similarly well in all didactical schemes (DS1-DS4), average scores vary between $0.77-0.82$. The last didactical scheme turned out to succeed worst. One reason might be the cumulative nature of tasks (all three earlier DS's were needed to produce the last one) and also the 
counter-intuitive nature of the phenomenon (single electron interference explained by the wavenature of electron).

Table 2. The average normalized scores of evaluated aspects in didactical schemes.

\begin{tabular}{lcccc}
\hline & DS 1 & DS 2 & DS 3 & DS 4 \\
\hline Nodes & 0.84 & 0.86 & 0.80 & 0.78 \\
Explanations & 0.81 & 0.84 & 0.72 & 0.75 \\
Clarity & 0.75 & 0.75 & 0.84 & 0.78 \\
\hline
\end{tabular}

There is smallish descent in the overall epistemic quality in the explanations of nodes in the DS3 and DS4. Closer inspection of this drop can be seen in Figure 3 which shows us that the amount of full scores is lowest in DS3. In comparison, around $85 \%$ of students have gained full or $75 \%$ of full scores in DS1 and DS2. Generally, in DS3 and DS4 the epistemic explanations are not that good.

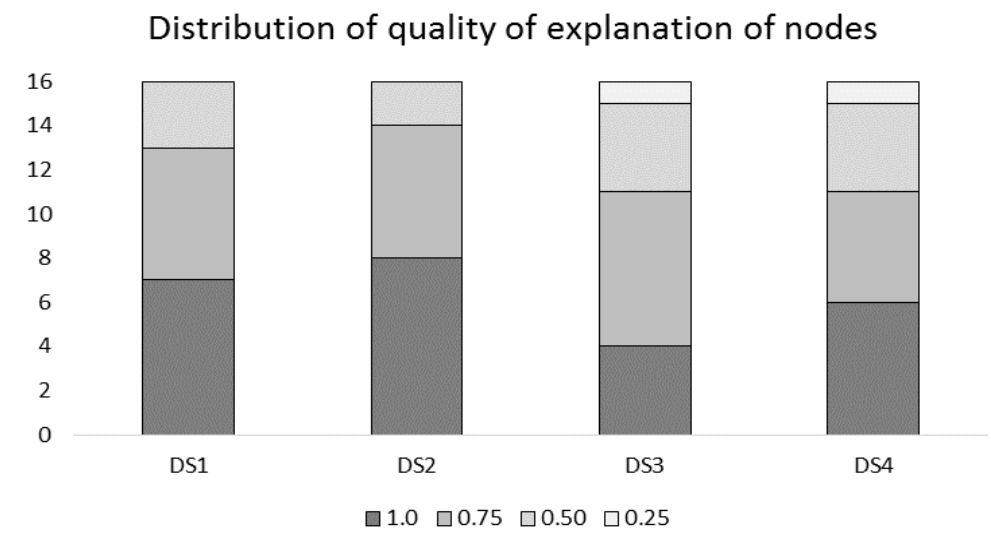

Figure 4. Bar chart describes the distribution of the epistemic quality of students' explanations in their four different didactical schemes. The amount of students $\mathrm{N}=16$.

The normalized sums of task points are presented in Table 1. Value close to 1 means that student have acquired almost full points of all tasks.

Table 3. Normalized scores describing the overall quality of knowledge justification schemes and didactical schemes of 16 students.

\begin{tabular}{lllllllllllllllll}
\hline KJS & 0.96 & 0.96 & 0.86 & 1.00 & 0.93 & 0.93 & 0.93 & 0.86 & 0.64 & 0.86 & 0.86 & 0.79 & 0.71 & 0.93 & 0.89 & 0.57 \\
DS & 1.00 & 0.80 & 0.60 & 1.00 & 0.85 & 0.90 & 0.98 & 0.75 & 0.73 & 0.65 & 0.88 & 0.80 & 0.75 & 0.70 & 0.85 & 0.53 \\
\hline
\end{tabular}

The Spearman's ranking correlation was calculated for normalized sum of all four separate KJS and DS scores and it was found to be 0.69 . Furthermore, the hypothesis that the data sets are independent can be rejected at the 5\% level based on the Spearman Rank test. Roughly, this means that one can conclude with $95 \%$ certainty that KJS and DS are dependent on each other.

From the Figure 4 we can see that there are some data points with relatively high KJS values $(<0.8)$ with lower DS values $(>0.7)$. On the other hand, we remark that the opposite does not exist (absence of data points having low KJS values with high DS values). 


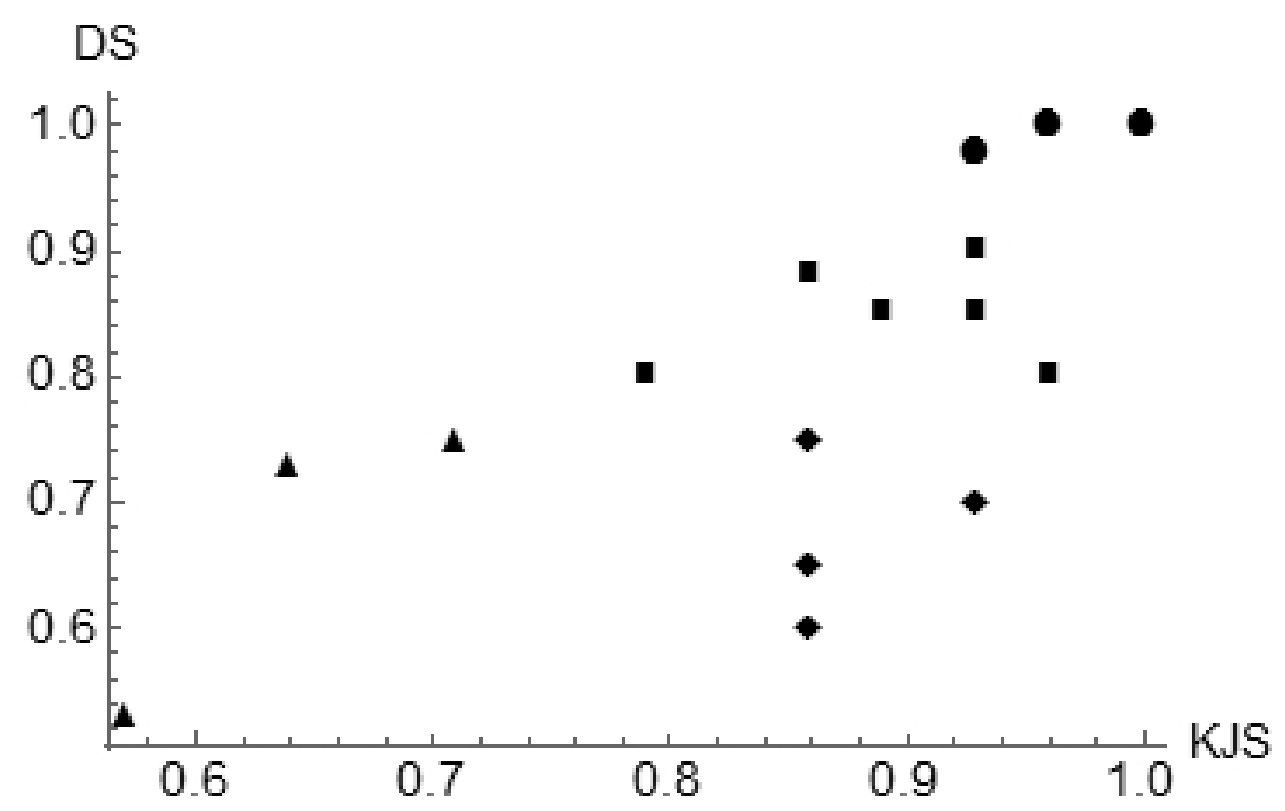

Figure 4. Scattering of normalized values of knowledge justification schemes (x-axis) and didactical schemes (y-axis). All KJS and DS values are summed up and normalized from 0 to 1 . Note the absence of values lower than 0.5. Different clusters are marked with different plot marker

Data can be grouped into four distinct clusters by agglomerative clustering analysis (Ruskeepää, 2004). Two different distance criteria (Euclidean and Manhattan) lead to exactly same clustering as it appears in Figure 4. Clusters are marked with different-shaped plot markers.

1. Low achievers (triangle). Student have low scores (0.55-0.70) in both KJS and DS.

2. Intermediate content knowledge, low usability (diamond). Students have quire high scores in KJS (0.85-0.95) but low scores (0.60-0.75) in DS. This means that these students have quite well identified the most relevant content knowledge in their KJS. The low usability of that knowledge means that students representations of its teaching plan (DS) are somewhat superficial either lacking many important nodes or adequate explanations. Note that according to cluster analysis, data point $(0.79,0.80)$ can either belong to cluster 2 or 3 .

3. High achievers (box). Student have quite high scores (0.80-0.95) in both KJS and DS. These students typically have some small shortcomings in their KJS's (in average one missing score in each KJS) and some important nodes or the explanations lack clarity at some points.

4. Excellent achievers (round). Students have full or almost full scores in both KJS and DS. These students were highly motivated to fully understand all phenomena.

The cluster analysis results go well along with the course grades, the threshold to get the best grade $(5 / 5)$ is $85 \%$ of maximum scores meaning that students in clusters 3 and 4 have got the highest grade of the course. Students in cluster 2 have got the second best grade and students in cluster 1 have got grade $3 / 5$. Only exception to this is the left-most data point who represent the lowest possible passing grade $(1 / 5)$ which describes the threshold of the skills and competencies our teacher education has set a teachers should have in command.

\section{Discussion and conclusions}

This research has presented guidelines to outline argumentation in teaching by using graphical schemes to 1) knowledge justification and 2) its didactical solution. The quality of knowledge justification schemes can be evaluated by following ideas of argumentative moves presented in van Lacum et al. (2014). The KJS's made of four different topics turned out to score quite well (in average 
0.82-0.88). Such heuristic can be used to evaluate knowledge justification but it could discern students views better if more attention is paid in the empirical evidence which is presented to support the claims. The quality of didactical schemes is measured by paying attention to the relevant connections between nodes and the degree of epistemic explanations supporting the nodes (Nousiainen, 2013).

Results show us indisputably that there is a clear correlation between KJS's and DS's scores. Therefore, the results allow us to state that KJS quality is a necessary prerequisite for DS quality. However, KJS quality is not an adequate condition to ensure the DS quality which means that the recognition of content knowledge does not automatically lead to didactical solution. This result is in accordance with Duit's and colleagues (2014) ideas of didactical reconstruction of knowledge. The ability to reorganize physics knowledge for teaching purposes is naturally one of the core skills that physics teacher education aims to. The novelty of this research is paying attention to the justification of knowledge claims as a teaching method but also a method to focus on physics content knowledge.

Previous research has discussed the advantages of fostering students' argumentation skills (e.g. Fischer et al. 2014). Especially paying careful attention to argumentative moves of written arguments (e.g. reading research articles) has shown to support students' abilities to discern the most essential parts of arguments and its structure (van Lacum et al., 2014). However, the results of this study corroborates the impression that understanding of core content knowledge is not enough but a didactical viewpoint is also needed in reorganization of content knowledge for teaching purposes. The goals of knowledge organization, its epistemic justification and coherent argumentation are of course central for physics teacher education and core competencies of a teacher. These competencies are fostered in physics teacher education by applying knowledge justification schemes and didactical schemes.

The data was collected from a teacher preparation course which was carried out by following a flipped classroom approach (for details, see e.g. Velegol et al., 2015; Toivola \& Silfverberg, 2015). The preservice teachers themselves were pleased with the approach that required active student participation and gave the responsibility of the learning to themselves (few examples below).

"We had to find out the things on our own and process that knowledge which almost inevitably leads to learning. Also, the lectures were planned so that the lecturer all the time communicated with the students. Students were free to present their own views and reflections and those were thought also trough together."

"It was especially advantageous to find out the theory [from research articles] on my own. I had to think thoroughly and therefore I also understood things much better."

The research results as well as the feedback from the course allows us to state that the presented tools force pre-service teachers to reflect their own knowledge, to take responsibility of their own learning process and help them to reorganize their physics knowledge for teaching purposes.

The presented knowledge justification schemes produce representations which are (after evaluation) quite alike with each other (gaining scores 0.70-1.00). Van Lacum's et al. (2014) framework has been a fruitful starting point of the research on students' abilities to recognise argumentative moves. Future research could concentrate more precisely on knowledge justification processes in physics emphasising the nature of physics knowledge. It would be interesting to develop a knowledge justification scheme which builds directly on the experimental and modelling processes which are two important processes in physics knowledge construction (Nousiainen \& Koponen, 2010). Such a scheme could better take into account the use of empirical evidence (cf. Sandoval \& Millwood, 2008; 
Kelly et al., 2008) and thus discern better the quality of students' argumentative representations. This kind of knowledge presentation would also help with construction of DS.

\section{References}

Cavagnetto, A. R., and Kurtz, K. J., (2016). Promoting Students' Attention to Argumentative Reasoning Patterns. Science Education, 100(4), 625-644.

Compton, A. H., (1961). The Scattering of X Rays as Particles. American Journal of Physics, 29, 817-820.

Duit, R., Schenker, H., Höttecke, D., and Niedderer, H., (2014). Teaching Physics. In N. G. Lederman and S. K. Abell (Eds.), Handbook of Research on Science Education, vol II (pp. 434-456). New York: Routledge.

Fischer, F., Kollar, I., Ufer, S., Sodian, B., Hussmann, H., Pekrun, R., Neuhaus, B., Dorner, B., Pankofer, S., Fischer, M., Strijbos, J.-W., Heene, M., and Eberle, J., (2014). Scientific Reasoning and Argumentation: Advancing an Interdisciplinary Research Agenda in Education. Frontline Learning Research, 5, 28-45.

Garcia-Mila, M., and Andersen, C., (2008). Cognitive Foundations of Learning Argumentation. In S. Erduran and M. P. Jiménez-Aleixandre (Eds). Argumentation in Science Education: Perspectives in Classroom-Based Research (pp. 29-46). The Netherlands: Springer.

Jiménez-Aleixandre, M. P., and Erduran, S., (2008). Argumentation in Science Education: An Overview. In S. Erduran and M. P. Jiménez-Aleixandre (Eds). Argumentation in Science Education: Perspectives in Classroom-Based Research (pp. 3-28). The Netherlands: Springer.

Kelly, G. J., Regev, J., and Prothero, W., (2008). Analysis of Lines of Reasoning in Written Argumentation. In S. Erduran and M. P. Jiménez-Aleixandre (Eds). Argumentation in Science Education: Perspectives in Classroom-Based Research (pp. 137157). The Netherlands: Springer.

Knight-Bardsley, A., and McNeill. K. L., (2016). Teachers' Pedagogical Design Capacity for Scientific Argumentation. Science Education, 100(4), 645-672.

Koponen, I. T., (2007). Models and Modelling in Physics Education: A Critical Re-analysis of Philosophical Underpinnings and Suggestions for Revisions. Science \& Education, 16, 751-773.

van Lacum, E. B., Ossevoort, M. A., and Goedhart, M. J., (2014). A Teaching Strategy with a Focus on Argumentation to Improve Undergraduate Students' Ability to Read Research Articles. CBE - Life Sciences Education, 13, 253-264.

Millikan, R. A., (1916). A Direct Photoelectric Determination of Planck's “ $h$ ". Physical Review, 7(3), 355-390.

Mäntylä, T., and Nousiainen, M., (2014). Consolidating Pre-service Physics Teachers' Subject Matter Knowledge Using Didactical Reconstructions. Science \& Education, 23(8), 1583-1604.

Nousiainen, M., (2013). Coherence of Pre-service Physics Teachers' Views of the Relatedness of Physics Concepts. Science $\mathcal{E}$ Education, 22(3), 505-525.

Nousiainen, M., and Koponen, I. T., (2010). Concept Maps Representing Physics Knowledge: Connecting the Structure and Content in the Context of Electricity and Magnetism. Nordic Studies in Science Education, 6, 155-172.

Rapanta, C., Garcia-Mila, M., and Gilabert, S., (2013). What is Meant by Argumentative Competence? An Integrative Review of Methods of Analysis and Assessment in Education. Review of Educational Research, 83(4), 483-520.

Rosa, R., (2012). The Merli-Missiroli-Pozzi Two-Slit Electron-Interference Experiment. Physics in Perspective, 14, 178-195.

Rueckner, W., and Titcomb, P., (1996). A Lecture Demonstration of Single Photon Interference. American Journal of Physics, 64(2), 184-188.

Ruskeepää, H., (2004). Mathematica Navigator: Mathematics, Statistics, and Graphs. New York: Elsevier Academic Press.

Sandoval, W. A., and Millwood, K. A., (2008). What Can Argumentation Tell Us About Epistemology? In S. Erduran and M. P. Jiménez-Aleixandre (Eds). Argumentation in Science Education: Perspectives in Classroom-Based Research (pp. 71-88). The Netherlands: Springer.

Toivola, M., and Silfverberg, H., (2015). Flipped Learning -Approach in Mathematics Teaching - A Theoretical Point of View. In P. Hestö and H. Silfverberg (Eds.), Proceedings of the Annual Symposium of the Finnish Mathematics and Science Education Research Association 2014 (pp. 93-102). http://www.protsv.fi/mlseura/julkaisut/malu_2014FINAL.pdf

Toulmin (1958/2003). The uses of argument. Cambridge: Cambridge university press.

Velegol S. B., Zappe, S. E., and Mahoney, E., (2015). The Evolution of a Flipped Classroom: Evidence-Based Recommendations. Advances in Engineering Education, 4(3), 1-37.

Zohar, A., (2008). Science Teacher Education and Professional Development in Argumentation. In S. Erduran and M. P. Jiménez-Aleixandre (Eds). Argumentation in Science Education: Perspectives in Classroom-Based Research (pp. 245268). The Netherlands: Springer. 